\title{
Risk Factors for Metabolic Bone Disease in Crohn's Disease Patients
}

\author{
Marilia Cravo, MD, PhD, ${ }^{*}$ Catarina Sousa Guerreiro, BSC, MS, ${ }^{+}$Paula Moura dos Santos, MD, ${ }^{\neq}$ \\ Miguel Brito, BSci, $\mathrm{PhD}_{,}^{+}$Paula Ferreira, $\mathrm{BSC}^{+}$Catarina Fidalgo, $\mathrm{MD},{ }^{*}$ Lourdes Tavares, $\mathrm{MD}{ }^{\neq}$ \\ and António Dias Pereira, MD*
}

Background: The aim was to evaluate the presence of metabolic bone disease (MBD) in patients with Crohn's disease (CD) and to identify potential etiologic factors.

Methods: The case-control study included 99 patients with CD and 56 controls with a similar age and gender distribution. Both groups had dual-energy $\mathrm{x}$-ray absorptionmetry and a nutritional evaluation. Single nucleotide polymorphisms at the IL1, TNF- $\alpha$, LT $\alpha$, and IL- 6 genes were analyzed in patients only. Statistical analysis was performed using SPSS software.

Results: The prevalence of MBD was significantly higher in patients $(P=0.006)$. CD patients with osteoporosis were older $(P$ $<0.005)$, small bowel involvement and surgical resections were more frequent $(P<0.005)$, they more often exhibited a penetrating or stricturing phenotype $(P<0.05)$, duration of disease over 15 years $(P<0.005)$, and body mass index (BMI) under $18.5 \mathrm{~kg} / \mathrm{m}^{2}(P<0.01)$ were more often found. No association was found with steroid use. Patients with a Z-score $<-2.0$ more frequently had chronic active disease $(P<0.05)$. With regard to diet, low vitamin $\mathrm{K}$ intake was more frequent $(P=0.03)$ and intake of total, monounsaturated, and polyunsaturated fat was higher in patients with $\mathrm{Z}$-score $<-2.0(P<0.05)$. With respect to genetics, carriage of the polymorphic allele for LT $\alpha 252 \mathrm{~A} / \mathrm{G}$ was associated with a higher risk of osteoporosis $(P=0.02)$. Regression analysis showed that age over 40 years, chronic active disease, and previous colonic resections were independently associated with the risk of developing MBD.

Conclusions: The prevalence of MBD was significantly higher in $\mathrm{CD}$ patients. Besides the usual risk factors, we observed that

Received for publication February 23, 2010; Accepted February 24, 2010.

From the *Instituto Português de Oncologia Francisco Gentil, Lisboa, Portugal, 'Escola Superior de Tecnologias da Saúde, Lisboa, Portugal, ${ }^{\ddagger}$ Hospital de Santa Maria, EPE, Lisboa, Portugal.

Supported in part by a grant from Sociedade Portuguesa de Gastrenterologia.

Reprints: Marília Cravo, MD, PhD, Serviço de Gastrenterologia, Instituto Português de Oncologia Francisco Gentil, Rua Professor Lima Basto, 1093 Lisboa codex, Portugal (e-mail: marilia.cravo@sapo.pt)

Copyright (c) 2009 Crohn's \& Colitis Foundation of America, Inc.

DOI 10.1002/ibd.21297

Published online 28 April 2010 in Wiley Online Library (wileyonlinelibrary.com). factors related to chronic active and long-lasting disease increased the risk of MBD.

(Inflamm Bowel Dis 2010;16:2117-2124)

Key Words: metabolic bone disease, Crohn's disease, etiologic factors

$\mathrm{M}$ etabolic bone disease (MBD), including osteopenia and osteoporosis, is frequently observed in patients with Crohn's disease (CD), ${ }^{1,2}$ but the pathogenesis of this common complication remains under discussion. Chronic inflammation, prolonged use of steroids, as well as low intake of calcium and vitamin $\mathrm{D}$ are among the most frequently implicated factors. ${ }^{2-5}$ In a previous case-control study that included 78 patients with $\mathrm{CD}^{6}$ we observed that a large proportion of patients had a restrictive diet in terms of dairy products and well as of vegetables and fruits, which resulted in a significantly lower intake of calcium, vitamin $\mathrm{D}$, and vitamin $\mathrm{K}$, as compared to controls, all these nutrients being fundamental for bone metabolism. ${ }^{7}$ In that same study we observed that patients with CD presented a significantly lower body mass index (BMI) as compared to controls and the prevalence of sedentarism was also higher in $\mathrm{CD}$ patients. ${ }^{6}$ These latter are also risk factors for MBD.

There is also evidence that chronic inflammation per se has a deleterious effect on bone mass ${ }^{2}$ and control of disease activity with modern biologic therapy results in an improvement of bone mineral density. ${ }^{9}$

Other investigators have focused on the role that genetic factors might play in the pathogenesis of this complication. There is now evidence that $\mathrm{CD}$ results from an imbalance between pro- and antiinflammatory cytokines, where the final result is a chronic and inappropriate inflammatory response to usual endoluminal stimuli such as bacterial flora and luminal nutrients. ${ }^{10,11}$ Previous studies showed that besides systemic inflammatory response, IL1 and IL-6 proinflammatory cytokines play a fundamental role in the paracrine stimulation of osteoclasts, thereby influencing the process of bone reabsorption. ${ }^{12,13}$ In a previous study Schulte et $\mathrm{al}^{14}$ observed that noncarriage of the 
240-basepair allele of the IL-1ra gene and carriage of the 130-basepair allele of the IL-6 were independently associated with increased bone loss. These observations further reinforce the hypothesis that systemic inflammation might also intervene in the pathogenesis of MBD in patients with $\mathrm{CD}$.

The aims of the present study were to 1) evaluate the prevalence of MBD in a group of patients with $\mathrm{CD}$ as compared to a group of healthy controls matched for age and sex, and 2) to analyze potential etiologic factors, namely, disease characteristics, therapies used for $\mathrm{CD}$, nutritional status, dietary intake, and genetic polymorphisms of cytokine genes.

\section{PATIENTS AND METHODS}

The study protocol was approved by the Ethics and Scientific Committees from both the Instituto Portugues de Oncologia Francisco Gentil (IPOFG) and from the University Hospital de Santa Maria, both located in Lisbon, Portugal. All subjects provided informed and written consent before entering the study.

Ninety-nine consecutive outpatients with a confirmed diagnosis of $\mathrm{CD}$ who were on a routine visit to the outpatient clinic during the period between September 2004 until November 2007 were asked to participate in the study. The diagnosis was based on previously defined criteria ${ }^{16}$ and disease activity was assessed according to the HarveyBradshaw Index (HBI). ${ }^{17}$ None of the patients were on steroids at the time of the study and none were hospitalized. Only patients with mild to moderate disease (HBI <7) were included. According to the HBI, 36/99 (36.4\%) of patients had moderately active disease with an $\mathrm{HBI} \geq 4$, whereas the remaining $63(63.6 \%)$ had inactive disease. These activity indices refer to at least 3 months/year. Patients with severe active disease (HBI >7) at the time of patient inclusion or with need of systemic steroids were excluded $(n=7)$. All patients had a stable body weight during the 3 months preceding the study. The control group included 56 healthy individuals, with a similar age and gender distribution (Table 1).

Physical activity was assessed using Jackson's questionnaire, ${ }^{18}$ which categorized subjects in three different levels: low (0), intermediate (1), and high (2). To improve statistical power and because physical activity was not evaluated in some patients and controls, we considered physical activity on two levels: sedentary versus intermediate/active.

\section{Bone Mineral Density (BMD) Assessment}

BMD was measured by dual-energy $x$-ray absorptionmetry (DXA) at the lumbar spine (second, third, fourth vertebrae) and at the proximal femur, both in patients and controls. All procedures were performed at two radiologic
TABLE 1. Demographic, Nutritional, and Osteodensitometry Analysis in Patients and Controls

\begin{tabular}{lccc}
\hline & $\begin{array}{c}\text { Patients } \\
(n=99)\end{array}$ & $\begin{array}{c}\text { Controls } \\
(n=56)\end{array}$ & $P$ \\
\hline Age & $40 \pm 14$ & $42 \pm 10$ & 0.35 \\
$\begin{array}{l}\text { Gender }- \\
\quad \text { F/M }\end{array}$ & $62 / 37$ & $37 / 19$ & 0.66 \\
Physical activity & & & \\
$\quad$ Yes/No & $40 / 59$ & $19 / 37$ & 0.35 \\
Smoking & & & \\
$\quad$ Yes/No & $50 / 49$ & $12 / 44$ & 0.000 \\
BMI (m \pm SD $)$ & $24.5 \pm 4.4$ & $24.3 \pm 4.1$ & 0.85 \\
BMI (kg/m $)(n)$ & & & \\
$\quad<18.5$ & $5 / 99$ & $2 / 56$ & \\
$\quad$ 19-25 & $58 / 99$ & $33 / 56$ & \\
$\quad>25$ & $36 / 99$ & $21 / 56$ & 0.69 \\
BMD - L & $1.23 \pm 0.5$ & $1.15 \pm 0.18$ & 0.18 \\
BMD - F & $0.94 \pm 0.31$ & $0.98 \pm 0.17$ & 0.31 \\
T-score L & $-1.12 \pm 1.13$ & $-0.35 \pm 1.20$ & 0.000 \\
T-score F & $-0.88 \pm 1.06$ & $-0.38 \pm 1.06$ & 0.01 \\
DXA & & & \\
$\quad$ Normal & $53(54 \%)$ & $44(80 \%)$ & \\
Osteopenia & $28(28 \%)$ & $9(14 \%)$ & \\
$\quad$ Osteoporosis & $18(17 \%)$ & $3(5 \%)$ & 0.006 \\
Z-score $<-2.0$ & $7(8 \%)$ & $1(2 \%)$ & 0.21 \\
\hline
\end{tabular}

centers for patient convenience. Reference values for men and women were supplied by Lunar Corp., referring to a normal white north European population (2588 white women and men aged 20-79 years). ${ }^{19,20}$ According to WHO, measurement of BMD by DXA is the "gold-standard" noninvasive method for the diagnosis of osteoporosis. ${ }^{21}$ The presence of MBD is defined using the number of standard deviations (SDs) from normal values of a young reference population, which is the T-score. A T-score lower than -2.5 is diagnostic for osteoporosis while a T-score between -2.5 and -1.0 means osteopenia. In contrast, the $\mathrm{Z}$-score is a comparison of the patient's BMD to an agematched population. A Z-score of -2.0 or lower is considered below the expected range for age and should prompt careful scrutiny for coexisting problems that may contribute to osteoporosis. ${ }^{22}$ In the present study we considered both T-score lower than 2.5 and Z-score lower than -2.0 as diagnostic for the presence of MBD, as the clinical significance of osteopenia is debatable.

\section{Dietary Intake}

Dietary intake was assessed using a semiquantitative food-frequency questionnaire, validated to the Portuguese population, ${ }^{23}$ consisting of 86 food items with nine possible 
answers with respect to the medium frequency intake (never or less than once a month, to six or more than six times a day); and three possible answers with regard to the size of the portion (smaller, equal, or larger than the medium portion size). Dietary intake was analyzed with a modified database Food Processor Plus software, v. 7 (ESHA Research, Salem, OR), which includes some Portuguese food items and allows the quantification of different macro- and micronutrients. Patients were asked to recall their dietary habits during the year prior to interview. In all, 44/99 patients were taking vitamin supplements: 23 were taking folate ( $1 \mathrm{mg} / 3$ times/week) and the remaining 21 patients were on a multivitamin supplement.

\section{Genotype Data}

Whole blood samples from CD patients were collected and kept at $-20^{\circ} \mathrm{C}$ until use. DNA extraction was performed with phenol/chloroform extraction. Polymerase chain reaction (PCR) and restriction fragment length polymorphism (RFLP) techniques were used to analyze gene polymorphisms in the IL-1, TNF- $\alpha, \mathrm{LT} \alpha$, and IL-6 genes. For the PCR reaction mixture, with a final volume of 20 $\mu \mathrm{L}$, we utilized $2 \mu \mathrm{L}$ of reaction buffer ([Taq buffer $\left.\left.+\left(\mathrm{NH}_{4}\right) 2 \mathrm{SO}_{2}\right] 10 \times\right), 2 \mu \mathrm{L} \mathrm{MgCl} 2(25 \mathrm{mM}), 2 \mu \mathrm{L}$ dNTPs (2 mM), $0.66 \mu \mathrm{L}$ of each primer $(6 \mu \mathrm{M}), 0.1 \mu \mathrm{L}$ of Taq DNA polymerase, $1-4 \mu \mathrm{L}$ of DNA depending on whether DNA was obtained from whole blood or through the Generation Capture Card Kit, and $\mathrm{H}_{2} \mathrm{O}$ until final volume. The primers in use were for IL $1 \beta-511 \mathrm{C} / \mathrm{T}\left(\mathrm{F}\right.$ : $5^{\prime}-\mathrm{CCCAG}$ CCAAGAAAGGTCAAT-3'/R: $5^{\prime}$-GTGGGACAAAGTGGA AGACA-3'), for IL $1 \beta+3953 \mathrm{C} / \mathrm{T}$ (F: $5^{\prime}$-TCCCAGCTTCAT CCCTACTG-3'/ R:3'-TGGAGGTGGAGAGCTTTCAG-3'), for TNF- $\alpha-857 \mathrm{C} / \mathrm{T}$ (F: 5'-AAGTCGAGTATGGGGACCC CCCGTTAA-3'/R: $5^{\prime}$-TTTCATTCTGACCCGGAGAC-3'), for TNF- $\alpha-308 \mathrm{G} / \mathrm{A}$ (F: 5'-AGGCAATAGGTTTTGAGG GCCAT-3'/R: 5'-AAAGTTGGGGACACACAAGC-3'), for LTA +252 A/G (F:5'-GCTTCGTGCTTTGGACTACC-3'/ R: 5'-AAGGTGAGCAGAGGGAGACA-3'), and for IL-6 -174G/C (F: 5'-TGCACTTTTCCCCCTAGTTG-3'/R: $5^{\prime}$-GCCTCAGACATCTCCAGTCC- $3^{\prime}$ ). IL1Ra is a VNTR of $86 \mathrm{bp}$. The following amplification protocol was used: denaturation at $95^{\circ} \mathrm{C}$ for 5 minutes, followed by 35 cycles of denaturation at $95^{\circ} \mathrm{C}$ for 45 seconds, annealing at $60^{\circ} \mathrm{C}$ for 30 seconds, and extension at $72^{\circ} \mathrm{C}$ for 1 minute, with a final extension step at $72^{\circ} \mathrm{C}$ for 10 minutes. The RFLP reaction mixture, with a final volume of $30 \mu \mathrm{L}$, consisted of $3 \mu \mathrm{L}$ of appropriate reaction buffer $(10 \times)$ (New England Biolabs, Beverly, MA), $0.5 \mu \mathrm{L}$ of DdeI (IL1 $\beta-511 \mathrm{C} / \mathrm{T})$, NcoI (TNF- $\alpha-308 \mathrm{G} / \mathrm{A})$, HincII (TNF- $\alpha-857 \mathrm{C} / \mathrm{T})$, HinfI (LT $\alpha+252 \mathrm{~A} / \mathrm{G})$, and NlaIII (IL-6), $1 \mu \mathrm{L}$ of BseYI (LT $\alpha$ $+80 \mathrm{C} / \mathrm{A}$ ) and $0.25 \mu \mathrm{L}$ of TaqI (IL1 $\beta+3953 \mathrm{C} / \mathrm{T}$ ) (New England Biolabs), $0.3 \mu \mathrm{L}$ BSA for specific enzymes (TaqI, HincII, NlaIII) and $\mathrm{H}_{2} \mathrm{O}$ until final volume. The reaction took place for 2 hours at $37^{\circ} \mathrm{C}$ for all polymorphisms except for IL $1 \beta+3953 \mathrm{C} / \mathrm{T}$, which was carried out at $65^{\circ} \mathrm{C}$. After digestion the product was run on a $4 \%$ gel and genotypes for each subject were recorded.

\section{Statistical Methods}

Statistical analysis was performed using SPSS v. 16.0 for Windows (Chicago, IL; EUA 2007) and included standard descriptive statistics, partial correlation, and multiple regression. Data were expressed as mean $\pm \mathrm{SD}$, as number of subjects and (percentage), or as odds ratio (OR) and 95\% confidence interval (CI). Bivariate analyses were conducted using Student's $t$-test or Mann-Whitney test for continuous and chi-square for categorical variables. Multiple regression analysis was used to examine the independent effects of demographic factors, disease characteristics, medications used to treat $\mathrm{CD}$, nutritional status, and intake on the existence of MBD. On multivariate analysis, regression models were adjusted for age and sex distribution, smoking habits, BMI, and steroid use. Statistical significance was established for $P<0.05$.

\section{RESULTS}

In Table 1 we show patient and control characteristics in terms of gender and age distribution, exercise and smoking habits, BMI, and DXA data. As shown, no significant differences were observed with respect to age and gender distribution, nor with respect to physical activity. However, a significantly higher proportion of patients were smokers $(P<0.0001)$. BMI was similar in patients and controls. BMD, both lumbar and femoral, were similar, but $\mathrm{Z}$ - and T-scores both in the spine and in the femur were significantly lower in patients. Accordingly, the prevalence of osteopenia was double in patients, while that of osteoporosis was more than 3 times as prevalent in patients as compared to controls.

As demographic distribution was similar in controls and patients, we tried to identify other possible factors that could explain the presence of MBD only in a subgroup of patients with CD. Table 2 shows patients and disease characteristics considering $\mathrm{T}$-scores lower or higher than -2.5 and $\mathrm{Z}$-score lower or higher than -2.0. If we consider a Tscore lower than -2.5 , we observed that older age, small bowel involvement, a penetrating or a structuring phenotype, previous surgical resections, and duration of disease greater than 15 years were all directly and significantly associated with the presence of osteoporosis. In contrast, previous steroid intake evaluated as total number of steroid pulses, number pulses/year of disease, or steroids during the previous year did not show any significant association with the presence of osteoporosis (Table 2). The same applies to the practice of physical exercise or smoking habits. With respect to therapies used, we observed that the 
TABLE 2. Clinical Features of CD Patients With or Without MBD

\begin{tabular}{|c|c|c|c|c|}
\hline & \multicolumn{2}{|c|}{ T-score } & \multicolumn{2}{|c|}{ Z-score } \\
\hline & $<-2.5$ & $>-2.5$ & $<-2.0$ & $>-2.0$ \\
\hline Mean age & $54.2 \pm 16.6$ & $38.5 \pm 13.0^{* *}$ & $50.7 \pm 10.7$ & $40.0 \pm 14.8^{*}$ \\
\hline \multicolumn{5}{|l|}{ Age } \\
\hline$<40$ years & $15 \%$ & $59 \%$ & $14 \%$ & $55 \%$ \\
\hline$\geq 40$ years & $85 \%$ & $41 \% * *$ & $86 \%$ & $45 \% *$ \\
\hline Gender (F/M) & $9 / 5$ & $23 / 44$ & $6 / 1$ & $26 / 40$ \\
\hline \multicolumn{5}{|l|}{ Disease location } \\
\hline Small bowel & $61 \%$ & $25 \%$ & $43 \%$ & $28 \%$ \\
\hline Ileocolonic & $31 \%$ & $57 \%$ & $43 \%$ & $54 \%$ \\
\hline Colonic & $8 \%$ & $18 \% *$ & $14 \%$ & $18 \%$ \\
\hline \multicolumn{5}{|l|}{ Phenotype } \\
\hline Inflammatory & $8 \%$ & $31 \%$ & $14 \%$ & $24 \%$ \\
\hline Penetrating & $39 \%$ & $34 \%$ & $43 \%$ & $38 \%$ \\
\hline Stricturing & $54 \%$ & $35 \% *$ & $43 \%$ & $38 \%$ \\
\hline \multicolumn{5}{|l|}{ Age at diagnosis } \\
\hline$<40$ years & $54 \%$ & $88 \%$ & $81 \%$ & $47 \%$ \\
\hline$\geq 40$ years & $46 \%$ & $12 \% * *$ & $19 \%$ & $53 \%$ \\
\hline \multicolumn{5}{|l|}{ Duration of disease } \\
\hline$\geq 15$ years & $69 \%$ & $29 \%$ & $43 \%$ & $35 \%$ \\
\hline$<15$ years & $31 \%$ & $71 \% * *$ & $57 \%$ & $65 \%$ \\
\hline Previous surgeries $(\%)$ & $77 \%$ & $42 \% *$ & $57 \%$ & $49 \%$ \\
\hline Small bowel surgeries $(n)$ & $3.5 \pm 3.8$ & $0.8 \pm 2.0 * *$ & $1.5 \pm 1.2$ & $1.3 \pm 2.7$ \\
\hline Colonic surgeries & $4.0 \pm 4.4$ & $0.5 \pm 1.9 * *$ & $0.5 \pm 0.57$ & $1.2 \pm 2.9$ \\
\hline Steroids past year $(\%)$ & $31 \%$ & $38 \%$ & $29 \%$ & $37 \%$ \\
\hline \# Pulses steroids $(n)$ & $6.8 \pm 12$ & $3.4 \pm 3.8$ & $4.7 \pm 5.5$ & $3.9 \pm 6.3$ \\
\hline \# Pulses steroids/year $(n)$ & $0.5 \pm 0.8$ & $0.3 \pm 0.3$ & $0.2 \pm 0.2$ & $0.3 \pm 0.4$ \\
\hline Use of budesonide $(n=43)$ & $30 \%$ & $16 \%$ & $50 \%$ & $16 \%$ \\
\hline Use of azathioprine $(n=65)$ & $54 \%$ & $87 \% * *$ & $57 \%$ & $83 \%$ \\
\hline Use of biologics $(n=13)$ & $17 \%$ & $16 \%$ & $33 \%$ & $15 \%$ \\
\hline \multicolumn{5}{|l|}{ Harvey-Bradshaw index } \\
\hline$\leq 4$ & $46 \%$ & $69 \%$ & $28 \%$ & $69 \%$ \\
\hline $4-7$ & $54 \%$ & $31 \%$ & $72 \%$ & $31 \% *$ \\
\hline \multicolumn{5}{|l|}{ Physical activity } \\
\hline Yes & $63 \%$ & $55 \%$ & $59 \%$ & $59 \%$ \\
\hline \multicolumn{5}{|l|}{ Smoking habits } \\
\hline Yes & $50 \%$ & $50 \%$ & $50 \%$ & $55 \%$ \\
\hline
\end{tabular}

use of azathioprine, which was present in 65/99 patients, was a protective factor regarding the presence of osteoporosis $(P=0.006)$. With regard to infliximab use no significant associations were observed $(P=0.96)$, although the number of patients treated with this drug was far too small to allow any definitive conclusions. However, 11/13 of the patients treated with infliximab did not have osteoporosis. When we considered patients with a Z-score lower or higher than -2.0 , the results were similar, although some differences did not reach statistical significance probably due to the fact that there were only seven patients with a $\mathrm{Z}$-score $<-2.0$. Interestingly, the disease activity index, which did not show any significant association for the presence of osteoporosis, was now significantly associated with a lower Z-score (Table 2). With smoking habits and physical activity no significant associations were observed.

When analyzing the association between MBD and the presence of polymorphic alleles either in homo- or 
TABLE 3. Nutritional Characteristics of Patients With or Without MBD

\begin{tabular}{|c|c|c|c|c|}
\hline & \multicolumn{2}{|c|}{ T-score } & \multicolumn{2}{|c|}{ Z-score } \\
\hline & $<-2.5$ & $>-2.5$ & $<-2.0$ & $>-2.0$ \\
\hline $\mathrm{BMI}\left(\mathrm{kg} / \mathrm{m}^{2}\right)$ & $23.5 \pm 4.3$ & $24.9 \pm 4.5$ & $23.4+3.7$ & $24.8 \pm 4.6$ \\
\hline $\mathrm{BMI}<18.5 \mathrm{~kg} / \mathrm{m}^{2}$ & $23 \%$ & $3 \% * *$ & $29 \%$ & $3 \% * *$ \\
\hline Total fat $(\mathrm{g} / \mathrm{d})$ & $82.0 \pm 32.7$ & $80.3 \pm 27.6$ & $101.9 \pm 29.1$ & $78.2 \pm 29.1 *$ \\
\hline Saturated fat $(\mathrm{g} / \mathrm{d})$ & $26.0 \pm 11.2$ & $26.5 \pm 10.6$ & $29.9 \pm 10.8$ & $25.9 \pm 11.1$ \\
\hline Monounsaturated fat $(\mathrm{g} / \mathrm{d})$ & $36.1 \pm 15.3$ & $34.8 \pm 12.2$ & $46.4 \pm 10.8$ & $33.7 \pm 12.9 * *$ \\
\hline N9 fatty acids $(\mathrm{g} / \mathrm{d})$ & $61.7 \pm 51.5$ & $46.1 \pm 37.4$ & $81.5 \pm 78.0$ & $47.0 \pm 39.1$ \\
\hline PUFA n6, n3 (g/d) & $13.0 \pm 6.5$ & $12.3 \pm 5.0$ & $17.3 \pm 7.1$ & $12.0 \pm 5.1^{*}$ \\
\hline Vitamin $\mathrm{D}(\mu \mathrm{g} / \mathrm{d})$ & $19.7 \pm 26.9$ & $19.0 \pm 47.8$ & $19.9 \pm 28.2$ & $19.1 \pm 46.5$ \\
\hline Vitamin $\mathrm{K}(\mu \mathrm{g} / \mathrm{d})$ & $10.0 \pm 8.9$ & $14.0 \pm 13.1^{*}$ & $12.9 \pm 10.9$ & $13.4 \pm 12.9$ \\
\hline Calcium (mg/d) & $692 \pm 652$ & $745 \pm 490$ & $733 \pm 723$ & $714 \pm 495$ \\
\hline
\end{tabular}

heterozygosity for the several cytokine genes analyzed, we observed that patients who carried the polymorphic allele for LT $\alpha 252 \mathrm{~A} / \mathrm{G}$ had a higher risk of presenting osteoporosis $(P=0.02)$, although the risk of having a $\mathrm{Z}$-score $<$ -2.0 did not reach statistical significance $(P=0.08)$. Also patients carrying the polymorphic allele of IL1Ra, the sole anti-inflammatory cytokine studied, had a tendency to present with a Z-score lower than $-2.0(P=0.06)$.

Table 3 shows nutritional status and nutrient intake in patients with or without bone disease. Although mean BMI was not significantly different in the patients with and without MBD, we observed that a higher proportion of patients with MBD were malnourished (BMI $<18.5 \mathrm{~kg}$ / $\mathrm{m}^{2}$ ). No differences were observed with respect to energy, protein, or carbohydrate intake (data not shown). However, significant differences were observed with respect to amount and type of fat intake when considering patients with a Z-score lower or higher than -2.0 . Very interestingly, we observed that total fat intake, monounsaturated and n6, n3 polyunsaturated fat intake was significantly higher in patients with a Z-score $<-2.0$. Monounsaturated $\mathrm{n} 9$ fat intake was also higher in this group of patients but not significantly so, probably due to the large SDs observed $(81 \pm 78$ versus $47 \pm 39 \mathrm{~g} /$ day; $P=0.12)$. Calcium and vitamin $\mathrm{D}$ intakes were low in both groups of patients; $48 \%$ and $54 \%$ of patients had a low intake of calcium and vitamin $\mathrm{D}$, respectively, according to the RDI values. Vitamin $\mathrm{K}$ intake was also under RDI in $50.6 \%$ and this proportion was significantly higher in patients with osteoporosis $(P=0.03)$.

Table 4 shows by univariate analysis which factors were associated with higher or lower risk of presenting a T-score lower than -2.5 or a Z-score lower than -2.0 . Older individuals, at diagnosis, longer duration of disease, more severe disease with higher HBI scores, and a higher number of previous surgeries were all risk factors for MBD. From a nutritional point of view, low intake of vitamin $\mathrm{K}$ and high intake of monounsaturated fat were the sole variables displaying a significant association with the risk of MBD. Carriers of the polymorphic allele for the $\mathrm{LT} \alpha 252 \mathrm{~A} / \mathrm{G}$ polymorphism were also at increased risk of osteoporosis. On multivariate analysis (Table 5) and adjusting for age and sex distribution, smoking habits, BMI, and previous steroid use, which are factors commonly

TABLE 4. Univariate Analysis for Factors Influencing the Presence of a T-score Lower than -2.5 or a Z-score Lower than -2.0

\begin{tabular}{|c|c|c|}
\hline & T-score $<-2.5$ & Z-score $<-2.0$ \\
\hline & OR, CI 95\% & OR, CI 95\% \\
\hline $\begin{array}{l}\text { Duration of disease }> \\
15 \text { years }\end{array}$ & $5.88(1.6-21.5)$ & $1.50(0.3-7.2)$ \\
\hline Age $>40$ years old & $8.25(1.6-40.3)$ & $7.94(0.9-69.3)$ \\
\hline $\begin{array}{l}\text { Age at diagnosis }>40 \\
\text { years old }\end{array}$ & $6.1(1.6-22.8)$ & $4.16(0.8-21.6)$ \\
\hline $\mathrm{HBI} \geq 4$ points & $2.82(0.8-9.5)$ & $6.0(1.1-33.8)$ \\
\hline $\begin{array}{l}\mathrm{LTA}+252 \mathrm{~A} / \mathrm{G} \\
\quad \text { (carriers) }\end{array}$ & $3.84(1.1-13.8)$ & $3.71(0.7-20.4)$ \\
\hline $\mathrm{BMI}>18.5 \mathrm{~kg} / \mathrm{m}^{2}$ & $0.11(0.02-0.71)$ & $0.07(0.01-0.62)$ \\
\hline Small bowel surgeries & $11.6(2.1-63.3)$ & $6.38(0.6-66.2)$ \\
\hline Colonic surgeries & $20.6(3.6-118.2)$ & $2.85(0.4-22.3)$ \\
\hline $\begin{array}{l}\text { Vitamin } \mathrm{K} \text { intake > } \\
\text { RDI }\end{array}$ & $0.24(0.06-0.96)$ & $0.38(0.7-2.1)$ \\
\hline $\begin{array}{l}\text { Increased intake of } \\
\text { Monounsaturated fat }\end{array}$ & $2.79(0.8-9.9)$ & $1.22(1.1-1.4)$ \\
\hline
\end{tabular}


TABLE 5. Multivariate Analysis for Patients Presenting with a T-score $<-2.5$ or a Z-score $<-2.0$ Adjusting for Age and Sex Distribution, Smoking Habits, BMl, or Previous Use of Steroids

\begin{tabular}{lllc}
\hline & T-score $<-2.5$ & & Z-score $<-2.0$ \\
\cline { 2 - 2 } & OR, CI 95\% & & OR, CI 95\% \\
\hline Age $>40$ years old & $7.91(1.5-42.3) *$ & & $5.54(0.5-53.5)$ \\
HBI $\geq 4$ points & $3.92(0.9-17.2)$ & & $15.9(1.2-188.9) *$ \\
Previous colonic & $8.85(1.26-61.8) *$ & 0 \\
$\quad$ surgeries & & \\
\hline$P<0.05$. & & \\
\hline
\end{tabular}

influencing the presence of MBD in the general population, we observed that only age above 40 years old, chronic active disease with $\mathrm{HBI} \geq 4$, and previous colonic surgeries were significantly associated with the presence of MBD.

\section{DISCUSSION}

MBD has long been described as a complication of inflammatory bowel disease, mainly of $\mathrm{CD}$, although the prevalence and the etiologic factors responsible for this complication remain under discussion. ${ }^{1-4}$ It is also debatable which is the most appropriate method to evaluate the presence of MBD in this group of patients. In the present study, DXA was used because it is the method recommended in the last consensus published by ECCO (European Crohn's and Colitis Organization). ${ }^{24}$ Because the clinical significance of osteopenia is unknown, since it does not inevitably progresses to osteoporosis, in the present study we used as the gold standard for the diagnosis of MBD the presence of osteoporosis (T-score $<-2.5$ ), which is clearly associated with an increased risk for fracture, or a Z-score lower than -2.0. The latter should prompt the identification of other coexisting problems which could contribute to osteoporosis, as recently suggested by the ISCD (International Society for Clinical Densitometry). ${ }^{22}$ Since in the present study we were aiming at identifying potential etiologic factors that could be responsible for the presence of MBD in certain patients with $C D$ but not in others, this parameter appeared particularly suitable for that purpose.

Previous studies have shown a prevalence of osteopenia and osteoporosis of $\approx 50 \%$ and $30 \%$, respectively, but the numbers vary widely. ${ }^{2}$ One reason for these discrepancies may be related to the fact that most of these studies do not include a control group. Because MBD is highly prevalent in the general population, in the present study we included a control group with a similar age and gender distribution, so that the magnitude of the problem could be more realistic. In comparison to our control group, we observed that our patient population had a prevalence of osteopenia that was double as compared to controls and a prevalence of osteoporosis that was three times greater. Previous studies identified a variety of factors that could increase the susceptibility for bone loss in this population, including inadequate diet and nutrition, long-term corticosteroid treatment, chronic inflammation per se, and genetic factors as well. ${ }^{2,8-14,25,26}$ In the present study we observed that, besides age, which applies to the general population, small bowel involvement, previous surgical resections, either colonic or involving the small bowel, duration of disease for more than 15 years, and a low intake of vitamin $\mathrm{K}$ were all positively associated with the presence of osteoporosis. The association with previous surgical resections was particularly striking. Because these associations were present both for small bowel as well as for colonic resections, we believe that these events may reflect a greater severity of disease as opposed to reflecting the possibility of a short bowel syndrome, as one might at first think. Dietary intake of calcium and vitamin $\mathrm{D}$ was low in $\approx 50 \%$ of CD patients included in the study, but most of these patients were taking these as supplements, which was not accounted for. This could be a reason for these variables not having a discriminative power to distinguish between patients having or not MBD.

With respect to steroids, the deleterious effects of corticosteroids on trabecular bone mass are well documented in some studies, but conflicting evidence comes from longitudinal and cross-sectional studies ${ }^{5,20,25,27,28}$ that failed to show any correlation between the rate of bone loss and steroid use. In a previous study, decreased bone mass was already present at the time of diagnosis ${ }^{29}$ in patients with $\mathrm{CD}$. In the present study we observed that the differences between T- and Z-scores in patients and controls were more marked at the level of the lumbar spine (trabecular bone) as compared with the hip (cortical bone), which could suggest that these differences could be related to steroid use. Due to the retrospective nature of our study, previous steroid use was difficult to quantify and three different approaches were used. No significant association was found between the presence of MBD evaluated either as a $\mathrm{T}$-score $<-2.5$ or a Z-score $<-2.0$ and previous steroid use. Some authors also raise the hypothesis whether steroid use is just a surrogate marker of more active and chronic disease. $^{9}$

Further supporting the role that chronic inflammation per se induces a greater loss of bone mass, we also observed that patients with active disease (HBI $\geq 4)$ and those with a penetrating or stricturing disease, which are usually more aggressive phenotypes, were also those with lower Z- and T-scores, respectively. Azathioprine use showed a protective effect, which also favors the hypothesis that controlling 
disease activity is beneficial to prevent MBD. In contrast, no effect was observed with the use of biological therapies but the number of patients treated with these drugs is far too small $(n=13)$. The beneficial effect of biologic therapies in improving $\mathrm{MBD}$ in patients with $\mathrm{CD}$ has been recently demonstrated. ${ }^{9}$

Because imbalances between pro- and antiinflammatory cytokines influence mechanisms of both chronic inflammation and bone reabsorption, previous studies have examined the relation between genetic polymorphisms in genes coding for these cytokines and increased propensity for bone loss. Schulte et $\mathrm{al}^{14}$ showed that in patients with $\mathrm{CD}$, noncarriage of a $240 \mathrm{bp}$ allele of the IL-1ra gene and carriage of the 130-bp allele of the IL- 6 gene were independently associated with increased bone loss. In the present study we only found significant associations with LT $\alpha 252 \mathrm{~A} / \mathrm{G}$ polymorphism, with carriers of the polymorphic allele presenting a higher risk for a $\mathrm{T}$-score $<-2.5$. Probably, either directly or indirectly by influencing disease activity, SNPs at pro- and antiinflammatory cytokines are potential promoter or protector factors with regard to MBD in patients with $\mathrm{CD}$.

One novel aspect of the present study was the association found between low Z-scores and fat intake. Thus, we observed that the amount of total fat as well as the type of fat intake seemed to differ in patients with a Z-score lower or higher than -2.0 . In a previous study performed in this same population, we observed that a high intake of total, monounsaturated fat, as well as a higher ratio of n6/n3 polyunsaturated fatty acids, were associated with a more active disease. ${ }^{15}$ Fat intake is now regarded as a potent immunomodulatory therapy in patients with $\mathrm{CD}^{30-35}$ either by modulating eicosanoid synthesis, by altering cell membrane fluidity, cell signal transduction, or even gene expression. More interestingly, Gassull et $\mathrm{al}^{30}{ }^{30}$ in a randomized controlled study performed in patients with active $\mathrm{CD}$, examined the effects of an n-6- versus an n-9-enriched diet as compared with conventional therapy with steroids. The study was prematurely stopped because, as opposed to what was expected, patients treated with an n-9-enriched diet had a much lower response rate compared with the other two groups. Later on, we also observed that a high intake of monounsaturated fat was associated with more active disease. ${ }^{15}$ In the present study, although in univariate analysis intake of monounsaturated fat was associated with increased risk of presenting a Z-score lower than -2.0 , multivariate analysis did not show that fat intake was an independent risk factor for MBD. Nonetheless, further studies are needed to clarify whether the amount and type of fat intake might influence the prevalence of MBD in patients with CD.

The results of the present study further support the concept that MBD is a frequent complication of CD.
Besides age and low body weight, which are also risk factors in the general population, we observed that factors associated with chronic, ongoing, and long-lasting inflammation are probably major risk factors for this complication. To our knowledge this is the first study that includes a control group with similar age and gender distribution, and which simultaneously analyzed demographic, genetic, clinical, and nutritional factors as possible etiologic factors in the pathogenesis of this complication.

\section{REFERENCES}

1. Adachi JD, Rostom A. Metabolic bone disease in adults with inflammatory bowel disease. Inflamm Bowel Dis. 1999;5:200-211.

2. Ali T, Lam D, Bronze MS, Humphrey MB.Osteoporosis in inflammatory bowel disease. Am J Med. 2009;122:599-604.

3. Bjarnson I.Metabolic bone disease in patients with inflammatory bowel disease. Rheumatology. 1999;38:801-306.

4. Siffledeen JS, Fedorak RN, Siminoski K, et al. Risk factors associated with low bone mineral density in patients with Crohn's disease. Inflamm Bowel Dis. 2004;10:220-228.

5. Reid IR. Glucocorticoid osteoporosis-mechanisms and management. Eur J Endocrinol. 1997;137:209-217.

6. Sousa-Guerreiro C, Cravo M, Costa AB, et al. A comprehensive approach to evaluate nutritional status in Crohn's patients in the era of biologic therapy: a case-control study. Am J Gastroenterol. 2007;102: 2551-2556.

7. Lanham-New SA. Importance of calcium, vitamin D and vitamin $\mathrm{K}$ for osteoporosis prevention and treatment. Proc Nutr Soc. 2008;67: $163-176$.

8. Sanada K, Miyachi M, Tabata I, et al. Differences in body composition and risk of life style-related diseases between young and older male rowers and sedentary controls. J Sports Sci. 2009;27:1027-1034.

9. Bernstein M, Irwin S, Greenberg GR. Maintenance infliximab treatment is associated with improved bone mineral density in Crohn's disease. Am J Gastroenterol. 2005;100:2031-2035.

10. Fiocchi C. Inflammatory bowel disease: etiology and pathogenesis. Gastroenterology. 1998;115:182-205.

11. Cominelli F, Pizarro TT. Interleukin-1 and interleukin-1 receptor antagonist in inflammatory bowel disease. Aliment Pharmacol Ther. 1996;10:49-53.

12. Manolagas SC, Jilka RL. Bone marrow, cytokines and bone remodeling. N Engl J Med. 1995;332:305-311.

13. Manolagas SC. Role of cytokines in bone resorption. Bone. 1995;17: $63 \mathrm{~S}-67 \mathrm{~S}$.

14. Schulte C, Dignass AU, Mann K, et al. Bone loss in patients with inflammatory bowel disease is less than expected: a follow-up study. Scand J Gastroenterol. 1999;34:696-702.

15. Guerreiro CS, Ferreira P, Tavares L, et al. Fatty acids, IL-6 and TNFa polymorphisms: an example of nutrigenetics in Crohn's disease. Am J Gastroenterol. 2009;104:2241-2249.

16. Lennard Jones JE. Classification of inflammatory bowel disease. Scand J Gastroenterol. 1989;24(suppl):2-6.

17. Harvey RF, Bradshaw JM. A simple index of Crohn's disease activity. Lancet. 1980;1:514.

18. Arroll B, Jackson R, Beaglehole. Validation of a three-month physical activity recall questionnaire with a seven-day food intake and physical activity diary. Epidemiology. 1991;2:296-299.

19. Kanis JÁ, Gluer CC. An update on the diagnosis and assessment of osteoporosis with densitometry. Committeee of Scientific Advisors, International Osteoporosis Foundation. Osteoporos Int. 2000;11:192-202.

20. Bernstein CN, Leslie WD, Leboff MS. AGA Technical review on osteoporosis in gastrointestinal diseases. Gastroenterology. 2003;124: 795-841.

21. Lewiechi EM, Watts NB, McClung MR, et al. Official position of the International Society for Clinical Densitometry. J Clin Endocrinol Metabol. 2004;89:3651-3655. 
22. Binkley N, Bilezikian JP, Kendler DL, et al. Summary of the International Society for Clinical Densitometry 2005 position development conference. J Bone Miner Res. 2007;22:643-647.

23. Reprodutibilidade e validação do questionário semiquantitativo de frequência alimentar. In Alimentação e Enfarte Agudo do Miocárdio: estudo caso-controlo de base comunitária. Tese de Doutoramento; Porto 2000. p 78-115.

24. Capprill R, Gassull MA, Escher JC, et al. European evidence based consensus on the diagnosis and management of Crohn's disease: special situations. Gut. 2006;55:(suppl 1):I35-58.

25. Bernstein CN, Leslie WD. The pathophysiology of bone disease in gastrointestinal disease. Eur J Gastroenterol Hepatol. 2003;15:857-864

26. Lee N, Radford-Smith GL, Forwood M, et al. Body composition and muscle strength as predictors of bone mineral density in Crohn's disease. J Bone Miner Metab. 2009;27:456-463.

27. Recommendations for the prevention and treatment of glucocorticoidinduced osteoporosis. American College of Rheumatology Task Force on Osteoporosis Guidelines. Arthritis Rheum. 1996;39:1791-1801.

28. Motley RJ, Crawley EO, Evans C, et al. Increased rate of spinal trabecular bone loss in patients with inflammatory bowel disease. Gut. 1988;29:1332-1336.
29. Schoon EJ, Blok BM, Geerling BJ, et al. Bone mineral density in patients with recently diagnosed inflammatory bowel disease. Gastroenterology. 1997;7:909-920.

30. Gassull MA, Fernandez-Banares F, Cabre E, et al. Fat composition may be a clue to explain the primary therapeutic effect of enteral nutrition in Crohn's disease: results of a double blind randomized multicentre European trial. Gut. 2002;51:64-68.

31. MacLean CH, Mojica WA, Newberry SJ, et al. Systematic review of the effects of n-3 fatty acids in inflammatory bowel disease. Am J Clin Nutr. 2005;82:611-619.

32. Esteve-Comas M, Gassull MA. Abnormal fatty acid status in patients with Crohn disease. Am J Clin Nutr. 2001;73:661-662 [Letter].

33. Cabre E, Gassull MA. Nutritional and metabolic issues in inflammatory bowel disease. Curr Opin Clin Nutr Metab Care. 2003;6: 569-576.

34. Belluzzi A, Bringole C, Campieri M, et al. Effects of an enteric coated fish oil preparation on relaps in Crohns disease. $N$ Engl J Med. 1996;334:1557-1560.

35. MacLean CH, Mojica W, Newberry SJ, et al. Systematic review of effects of n-3 fatty acids in inflammatory bowel disease. Am J Clin Nutr. 2005;82:611-619. 